Article

\title{
Phytotoxicity of Corncob Biochar before and after Heat Treatment and Washing
}

\author{
Kiatkamjon Intani *ㅁ, Sajid Latif, Md. Shafiqul Islam and Joachim Müller@ \\ University of Hohenheim, Institute of Agricultural Engineering, Tropics and Subtropics Group (440e), \\ Stuttgart 70599, Germany; s.latif@uni-hohenheim.de (S.L.); msislamdebd@yahoo.com (M.S.I.); \\ joachim.mueller@uni-hohenheim.de (J.M.) \\ * Correspondence: k_intani@uni-hohenheim.de or info440e@uni-hohenheim.de; Tel.: +49-711-459-23114
}

Received: 27 September 2018; Accepted: 18 December 2018; Published: 21 December 2018

\begin{abstract}
Biochar from crop residues such as corncobs can be used for soil amendment, but its negative effects have also been reported. This study aims to evaluate the phytotoxic effects of different biochar treatments and application rates on cress (Lepidium sativum). Corncob biochar was produced via slow pyrolysis without using purging gas. Biochar treatments included fresh biochar (FB), dried biochar (DB), washed biochar (WB), and biochar water extract (WE). Biochar application rates of 10,20, and $30 \mathrm{t} /$ ha were investigated. Significant phytotoxic effects of biochar were observed on germination rates, shoot length, fresh weight, and dry matter content, while severe toxic effects were identified in FB and WE treatments. Germination rate after $48 \mathrm{~h}\left(\mathrm{GR}_{48}\right)$ decreased with the increase of biochar application rates in all treatments. The observed order of performance of the biochar treatments for germination, shoot length, and shoot fresh weight for every biochar application rate was $\mathrm{WB}>\mathrm{DB}>\mathrm{WE}>\mathrm{FB}$, while it was the reverse order for the shoot dry matter content. WB treatment showed the best performance in reducing the phytotoxicity of biochar. The mitigation of the phytotoxicity in fresh corncob biochar by washing and heat treatment was found to be a simple and effective method.
\end{abstract}

Keywords: biochar; crop residue; corncob; germination; phytotoxicity; self-purging pyrolysis; soil amendment

\section{Introduction}

Corncob is biomass residue, which is available and underused in many countries including Ethiopia [1,2]. It was reported in a previous study that in the corn belt areas of Ethiopia the average annual corn stover (i.e., cobs, husks, leaves and stalks) production per household was 2.09 tons [3]. In developing countries, corn is still harvested manually. The cobs with kernels are picked, dried, and stored. After shelling the kernels, the corncobs are available for other uses without extra effort for the collection and transportation. Therefore, corncobs have a potential to be processed into biochar for both energy and soil improvement via a slow pyrolysis process. This can improve the resource use efficiency along the biomass-based value webs. Corncob biochar could have an innovative use as propagation substrate in agricultural production systems [4,5].

In general, slow pyrolysis process requires a purging gas (e.g., nitrogen) to obtain oxygen-limited condition in the system [6]. The unaffordability and poor accessibility of pure nitrogen could hinder the establishment of biochar systems for smallholders in developing countries [7]. There are limited numbers of studies on pyrolysis without using nitrogen as purging gas (self-purging pyrolysis) [8,9]. Therefore, the need exists for studies on the possibility of producing biochar via slow pyrolysis without using purging gas. To address the existing knowledge gap, the production and characterization of corncob biochar from a self-purging pyrolysis reactor was carried out in previous studies of the 
authors $[10,11]$. It was proven that a self-purging pyrolysis reactor effectively produced corncob biochar with acceptable quality. However, in order to avoid negative effects of corncob biochar on plants and soils, phytotoxicity tests should be carried out before the biochar will be applied. Cress seeds are widely used for germination and toxicity tests due to their specific characteristics such as rapid growth and response, affordability, and hydroponic characteristics [12-15]. Cress seeds were also selected by Rombolà et al. [16] for a study to identify the phytotoxicity of biochars derived from poultry litter and corn stalk. To compare the results with previous studies, cress seeds were used in the present study for the germination test.

In recent years, biochar has gained substantial attention for its potential use as carbon sequestration, soil improver and biofuel. The concept of using biochar as a soil improver was established based on the research on Amazonia Dark Earths (Terra Preta) [17]. It was proved by several studies that agriculture, environment, and energy sectors can benefit from various applications of biochar [18,19]. However, increasing numbers of studies reported negative effects and dubious benefits of biochar for agricultural applications and carbon sequestration under field conditions [20,21]. More research on biochar derived from different biomass feedstocks is required before applying biochar to different types of soils under various climate conditions [22]. Moreover, the existence of potential contaminants in biochar was also reported in previous studies. Polycyclic aromatic hydrocarbons (PAHs), volatile organic compounds (VOCs), heavy metals ( $\mathrm{Cd}, \mathrm{Cr}, \mathrm{Cu}, \mathrm{Ni}, \mathrm{Pb}$, and $\mathrm{Zn}$ ), tars, furans, and dioxins were the conventional pollutants that could be present in biochar [23,24]. These pollutants were commonly formed during pyrolysis and might exist at a low concentration with less bioavailability since they could be absorbed by the biochar [23-26]. A few studies on the composition and impact of residual tars and VOCs were carried out [27-29]. It was determined that biochar containing leachable organic compounds showed positive effects on corn productivity [30], while negative effects on aquatic microorganisms were observed [27]. The contamination of biochar during pyrolysis was caused by the re-condensation of the VOCs, which condensed into liquid products. These liquids were the degradation products of lignin, cellulose, and hemicellulose during the pyrolysis process [31], which contained acetone, acetic acid, methanol, and furfural. The other substances such as alcohols, aldehydes, furans, ketones, organic acids, and phenols were among the main compounds found in the liquids. Furthermore, PAHs could also be found in the liquid products from the pyrolysis process [31,32]. In the case of biochar toxicity, many studies focused on PAHs and heavy metals [33]. VOCs such as acetone and benzene in biochar were found to have severe phytotoxic effects $[29,33]$. In the presence of transition metals such as $\mathrm{Cr}, \mathrm{Cu}, \mathrm{Fe}, \mathrm{Pb}$, and $\mathrm{Zn}$ in the biomass feedstock, free radicals were generated during pyrolysis [25]. These free radicals reacted with water and formed reactive oxygen species, which could have negative effects on seed germination, root-shoot elongation and plant growth [25]. Liao et al. [25] also reported that free radicals in biochar had more detrimental effects on seed germination than the PAHs and heavy metals. Salinity in biochar was also found to have a negative effect on seed germination and seedling growth due to osmotic stress $[34,35]$. The biochar salinity was usually estimated by electrical conductivity (EC) [36]. It was evident that salt stress induced by high salinity in biochar significantly inhibited seed germination [16]. Moreover, the alkaline nature of biochar indicated by a high $\mathrm{pH}$ value might lead to an insolubilization of plant nutrients [34,37].

Previous studies were carried out to identify methods to reduce biochar phytotoxicity [37,38]. It was reported that washing biochar with water or an organic solvent significantly reduced its toxicity. In this washing process, an aqueous extract was separated from the solid biochar [37,39]. It should be noted that VOCs in biochars derived from different feedstocks at high temperatures $\left(800-860^{\circ} \mathrm{C}\right)$ did not inhibit germination of barley [37]. It was also evident that biochar produced at a higher temperature had less phytotoxic effects than biochar produced at a lower temperature [6]. VOCs in biochar could be reduced by handling, processing, and long-term storage [38,40]. A previous study by Kołtowski and Oleszczuk [41] showed that biochar toxicity was also reduced by drying the biochar at 100 to $300{ }^{\circ} \mathrm{C}$ for $24 \mathrm{~h}$. However, biochar toxicity and phytotoxicity mitigation methods have not yet 
been widely studied on biochar produced in a self-purging pyrolysis. Therefore, the need exists to assess the toxicity of the fresh corncob biochar before any agricultural applications. Furthermore, it is also necessary to identify whether simple washing and heat treatments can adequately reduce the phytotoxicity of corncob biochar produced in a self-purging pyrolysis reactor. After washing biochar, the biochar water extract might have high environmental risks. Thus, the phytotoxicity of the biochar water extract should be also assessed, which will provide useful information for a proper management of the water extract. This can avoid the contamination to soils, ground water, and the ecosystems.

It should be noted that while biochar might offer potential benefits, there are also risks arising from its applications. Therefore, biochar properties must be carefully evaluated before field applications. Different treatments such as heat treatment and washing could be options for the reduction of the phytotoxicity in biochar. In this study, the physiochemical properties of the corncob biochar were determined. The objective of this study was to investigate the phytotoxic effects of different biochar treatments on seed germination of cress (Lepidium sativum). Fresh biochar (FB), dried biochar (DB), washed biochar (WB), and biochar water extract (WE) with the application rates of 10, 20, and $30 \mathrm{t} / \mathrm{ha}$ were investigated. The phytotoxic effects on germination rates, shoot length, fresh weight, and dry matter content of cress seedlings were identified.

\section{Materials and Methods}

\subsection{Biomass and Biochar Preparation}

Corncobs were provided by the experimental station of the University of Hohenheim (Heidfeldhof, $48^{\circ} 42^{\prime} 56^{\prime \prime} \mathrm{N} 9^{\circ} 11^{\prime} 29^{\prime \prime} \mathrm{E}, 396 \mathrm{~m}$ a.s.l.). The corncobs were collected from cultivars being used for animal feed. The cobs without kernels were collected manually after being discarded from a combine harvester. The biomass was dried at the experimental station and stored in a wooden box with a perforated floor.

A self-purging pyrolysis reactor was used for the pyrolysis experiments as presented in previous studies $[10,11]$. The reactor was constructed of stainless steel with inner dimensions of 22.6, 15.6, and $9.8 \mathrm{~cm}$ in length, width, and height, respectively. Various sizes of holes on the lid of the reactor were used as pyrolysis gas outlets. In the present study, a hole with a diameter of $6 \mathrm{~mm}$ was selected. The pyrolysis reactor was placed in a pyrolysis chamber during the experiments. A gas outlet pipe was attached to the pyrolysis chamber with inner dimensions of 25,18 , and $10 \mathrm{~cm}$ (length, width, and height). The pyrolysis unit was heated in an ashing furnace (LVT 15/11/P330, Nabertherm GmbH, Lilienthal, Germany).

In total $3.7 \mathrm{~kg}$ of whole corncobs without size reduction were pyrolyzed in 8 batches. The corncob biomass was heated from 100 to $450{ }^{\circ} \mathrm{C}$ at a heating rate of $10{ }^{\circ} \mathrm{C} / \mathrm{min}$. The pyrolysis temperature was kept at $450{ }^{\circ} \mathrm{C}$ for $60 \mathrm{~min}$ without using a purging gas. After removing the pyrolysis reactor from the furnace, it was covered with aluminum foil to avoid further oxidation and cooled down for $30 \mathrm{~min}$ at room temperature. Those operating conditions have been chosen to obtain corncob biochar with a low volatile matter content, high fixed carbon content, high heating value, high $\mathrm{pH}$, high $\mathrm{EC}$, and high biochar yield [11].

\subsection{Characterization of Corncob Biochar}

The biochar yield was calculated on air-dried basis (ad), as follows:

$$
Y_{\text {biochar, ad }}=100 \times \frac{M_{\text {biochar }}}{M_{\text {biomass }}}
$$

where $Y_{\text {biochar,ad }}$ is the air-dried basis yield of biochar (\%), $M_{\text {biochar }}$ represents the mass of produced biochar (g), and $M_{\text {biomass }}$ represents the total mass of biomass (g).

Biochar was ground using a coffee mill (CM3260, GRUNDIG Intermedia GmbH, Neu-Isenburg, Germany) and sieved to obtain a particle size of $<2 \mathrm{~mm}$. The biochar samples were thoroughly mixed in a plastic container before random samples were taken for the analyses of physicochemical 
properties and germination test. The analyses of the physicochemical properties of the biochar were done in triplicate. The oven drying method based on DIN 51718 [42] was used to determine the moisture content $(\mathrm{MC})$ of the biochar. The analysis of volatile matter content $(\mathrm{VM})$ was carried out according to the standard methods DIN 51720 [43], while the ash content (AC) of the biochar was determined based on DIN 51719 [44]. The calculation of the fixed carbon content (FC) was done using the following equation:

$$
F C=100-V M-A C
$$

The $\mathrm{pH}$ values were measured in a biochar solution. Approximately $0.5 \mathrm{~g}$ of biochar and $5 \mathrm{~mL}$ of $0.01 \mathrm{~mol} / \mathrm{L} \mathrm{CaCl}_{2}$ solution were mixed. After shaking the biochar solution for an hour, the $\mathrm{pH}$ values were determined using a $\mathrm{pH}$ meter (HQ40D, Hach Company, Colorado, USA). The EC was determined in the biochar water extract $(1: 10 \mathrm{w} / \mathrm{v})$ using an electrical conductivity meter (Cond 315i/SET, Xylem Analytics Germany Sales GmbH \& Co. KG, Weilheim, Germany).

The elemental analyzer (vario Max CNS, Elementar Analysensysteme GmbH, Langenselbold, Germany) was used to measure the $\mathrm{C}, \mathrm{N}$, and $\mathrm{S}$ content. Inductively coupled plasma optical emission spectrometry (ICP-OES) (Vista-PRO, Varian Inc., California, USA) was employed to estimate the major extractable mineral cations such as $\mathrm{Al}, \mathrm{Ca}, \mathrm{Fe}, \mathrm{Mg}, \mathrm{Mn}, \mathrm{Na}, \mathrm{Zn}$, and $\mathrm{P}$. Whereas, an inductively coupled plasma mass spectrometry (ICP-MS) (NexION 300X, PerkinElmer Inc., Massachusetts, USA) was used to determine the water extractable trace elements such as $\mathrm{Cd}, \mathrm{Co}, \mathrm{Cr}, \mathrm{Cu}, \mathrm{Ni}, \mathrm{Pb}, \mathrm{Rb}$, and $\mathrm{Sr}$. The effective cation exchange capacity (ECEC) was determined by simultaneous ICP-OES applying $1 \mathrm{M}$ ammonium chloride extraction based on the handbook forest analytics (HFA) method A3.2.1.8 [45]. The ECEC was calculated by summing the exchangeable cations of $\mathrm{Al}, \mathrm{Ca}, \mathrm{Fe}, \mathrm{K}, \mathrm{Mg}, \mathrm{Mn}$, and $\mathrm{Na}$.

\subsection{Treatments of Corncob Biochar}

Phytotoxic potential was determined before and after heat treatment and washing. Untreated biochar further on is referred to as FB. Heat treatment was applied to reduce VOCs and PAHs [41], and to change physicochemical properties such as hydrophobicity and hydrophilicity [38]. For this purpose biomass was oven dried according to DIN 51,718 [42] at $105( \pm 2)^{\circ} \mathrm{C}$ for $24 \mathrm{~h}$ and then placed in a desiccator for $30 \mathrm{~min}$. The samples were stored in airtight containers until use. The heat-treated biochar is further on referred to as DB. To reduce water-soluble toxic compounds in the solid phase [37,39], biochar was also washed. The fresh biochar was mixed with $24 \mathrm{~mL}$ of de-ionized water and manually shaken for $1 \mathrm{~min}$. The biochar suspension was shaken in the lab shaker (Type 1083, Gesellschaft für Labortechnik mbH, Burgwedel, Germany) for $24 \mathrm{~h}$ at room temperature. Subsequently, the solid and liquid fractions in the biochar suspension were separated using the filter paper (Filter discs, Grade 388, Pore size 10-15 $\mu \mathrm{m}$, Sartorius Stedim Biotech GmbH, Göttingen, Germany) and vacuum pump (N 035.3 AN. 18, KNF Neuberger GmbH, Freiburg, Germany). As a result, WB and biochar WE were obtained and used for the germination test. The WE treatment was used to identify the potential environmental risks and contamination, which could be caused by the leaching effect of fresh biochar. For the control (CON), sand without the addition of biochar was taken.

\subsection{Germination Test}

Cress seeds were acquired from Bruno Nebelung GmbH, Everswinkel, Germany. The company reported a germination rate of $99 \%$ for the seeds. A pre-test revealed a germination rate of $97 \%$.

Plastic mini greenhouses each holding one planting tray of $57 \times 38 \times 18 \mathrm{~cm}$, (Maximus Complete, Romberg GmbH \& Co. KG, Ellerau, Germany) were set for the germination tests. The mini greenhouse was equipped with two illumination units ( 24 watt, 6400 Kelvin). A heat mat ( $50 \times 30 \mathrm{~cm}, 30$ watt) was used to control the temperature in the mini greenhouse. A control unit was employed to regulate the temperature and lighting (HortiSwitch Thermostat, Romberg GmbH \& Co. KG, Ellerau, Germany). 
Sand with a particle size of $0.6-1.4 \mathrm{~mm}$ in diameter was used. The sand was disinfected in the pyrolysis reactor at $600^{\circ} \mathrm{C}$ for $3 \mathrm{~h}$.

The germination test was carried out using a block design. The experiment was performed with three and four replications for treatments and control (CON), respectively. Two mini greenhouses were assigned as block 1 and block 2 . A seedling tray with 20 germination pots was placed in each of the mini greenhouse. The size of each germination pot was $5 \mathrm{~cm} \times 4 \mathrm{~cm}$. A total of 16 germination pots were used for the replications in this experiment as described in Table 1 . Three application rates for biochar were selected, namely 2, 4, and $6 \mathrm{~g}$ of biochar per pot representing 10, 20, and $30 \mathrm{t} / \mathrm{ha}$, respectively. The application rates were determined according to the assumption that the biochar was incorporated into the soil over a depth of $50 \mathrm{~mm}$ [46]. Each germination pot of the mini greenhouse was filled with a mixture of $100( \pm 0.05) \mathrm{g}$ disinfected sand, $24 \mathrm{~mL}$ de-ionized water and 2, 4, and $6 \mathrm{~g}$ of biochars FB, DB, and WB as shown in Table 1. Also, the biochar WE was tested by mixing $100( \pm 0.05)$ g disinfected sand with $24 \mathrm{~mL} \mathrm{WE}$, where 2,4 , and $6 \mathrm{~g}$ of biochar were washed with de-ionized water. This corresponds to 83,167 and $250 \mathrm{~g}$ biochar washed in $1 \mathrm{~L}$ water.

Table 1. Experimental set-up.

\begin{tabular}{cccccc}
\hline \multirow{2}{*}{ Treatments } & & \multicolumn{2}{c}{ Block 1 and 2 } & Biochar & Extract \\
\cline { 3 - 6 } & & Replications & Seeds per replication & (g) & (g/L) \\
\hline Control & $(\mathrm{CON})$ & 4 & 5 & - & - \\
Fresh biochar & $(\mathrm{FB})$ & 3 & 5 & $2,4,6$ & - \\
Dried biochar & $(\mathrm{DB})$ & 3 & 5 & $2,4,6$ & - \\
Washed biochar & $(\mathrm{WB})$ & 3 & 5 & $2,4,6$ & - \\
Biochar water extract & (WE) & 3 & 5 & - & $83,167,250$ \\
\hline
\end{tabular}

The sand, biochar, and de-ionized water or WE were filled into a plastic bottle and manually shaken for 45 seconds before filling the germination pot with the mixture. The moisture content in the substrate was maintained at $85 \%$ of the maximum water holding capacity (WHC) of the sand [47].

There were three runs for the whole experiment, in which the three application rates were performed separately. The germination period lasted 7 days under $24 \mathrm{~h}$ continuous lighting, 5500-7500 lux [48] and controlled temperatures of $23( \pm 2)^{\circ} \mathrm{C}$. The distance between the lamp (T5HO 24 watt, PAR white 2400K, Romberg GmbH \& Co. KG, Ellerau, Germany) and the top of the germination pot was $25 \mathrm{~cm}$. Total numbers of germinated seeds were counted after $24 \mathrm{~h}$ and $48 \mathrm{~h}$. The normal and abnormal seedling emergence and above-ground biomass (fresh and dry shoot weight, shoot length) were evaluated [49].

Germination rate (GR) was defined as a percentage of the germinated seeds to the total seeds within $24 \mathrm{~h}\left(\mathrm{GR}_{24}\right)$ and $48 \mathrm{~h}\left(\mathrm{GR}_{48}\right)$. A seed was considered as germinated when there was visible root development [35]. The above-ground biomass of cress was collected. The shoot length ( $\mathrm{mm}$ ) was measured using a digital slide caliper (M 823-160, Brüder Mannesmann Werkzeuge GmbH, Remscheid, Germany). The fresh weight of the shoot biomass was measured in grams using a digital balance (ED224S, Sartorius AG, Göttingen, Germany). Subsequently, the biomass was dried in an oven at $105( \pm 2)^{\circ} \mathrm{C}$ for $24 \mathrm{~h}$ and the dry weight was recorded. Finally, the MC and dry matter content (DM) of the shoot biomass were calculated.

\subsection{Statistical Analysis}

Generalized linear mixed model (GLMM) using the GLIMMIX procedure in statistical analysis system (SAS) (Ver. 9.3, SAS Inst., Cary, NC, USA) was employed for the statistical analysis. The analysis of variance (ANOVA) and the comparison of means using least significant difference (LSD) were evaluated at $95 \%$ confidence level $(p<0.05)$. 


\section{Results and Discussion}

\subsection{Characteristics of Corncob Biochar}

The biochar yield was $26.42 \pm 0.91 \%$. The results of the proximate analysis, $\mathrm{pH}$, and EC of the biochar are presented in Table 2. The biochar particle distribution is also shown in Table 2. The biochar yield in our study $(26.42 \%)$ was similar to the results in a previous study, which reported biochar yields of 25-27\% [6]. This confirmed that the pyrolysis of corncob without using purging gas produced similar amounts of solid products. Özçimen and Ersoy-Meriçboyu [50] reported that the biochar yield decreased linearly with an increase in the purging gas flow rate. This might be explained by the removal of the volatile matters from the feedstock, which reduced the secondary reaction such as re-polymerization and re-condensation. However, the impact of the purging gas on the biochar yield was not highly significant. On the other hand, there might be a risk of high VM in biochar in the absence of purging gas during pyrolysis, which might increase the phytotoxic substances [10,11].

Table 2. Proximate analysis, $\mathrm{pH}, \mathrm{EC}$, and particle size distribution of the corncob biochar.

\begin{tabular}{ccc}
\hline Parameters & Unit & Value \\
\hline Moisture content (MC) & wt. $\% \mathrm{db}^{\mathrm{a}}$ & $1.18 \pm 0.10$ \\
Volatile matter content (VM) & wt. $\% \mathrm{db}$ & $14.48 \pm 0.21$ \\
Ash content (AC) & wt. $\% \mathrm{db}$ & $6.52 \pm 0.06$ \\
Fixed carbon content (FC) & wt. $\%$ daf & $78.98 \pm 0.29$ \\
$\mathrm{pH}$ & - & $10.34 \pm 0.04$ \\
Electrical conductivity (EC) & $\mathrm{mS} / \mathrm{cm}$ & $7.21 \pm 0.05$ \\
Particle size & & \\
$\mathrm{CBP}>2 \mathrm{~mm}$ & $\%$ & 0.39 \\
$2 \mathrm{~mm} \geq \mathrm{CBP}>1 \mathrm{~mm}$ & $\%$ & 2.30 \\
$1 \mathrm{~mm} \geq \mathrm{CBP}>850 \mu \mathrm{m}$ & $\%$ & 2.12 \\
$850 \mu \mathrm{m} \geq \mathrm{CBP}>600 \mu \mathrm{m}$ & $\%$ & 7.96 \\
$600 \mu \mathrm{m} \geq \mathrm{CBP}>500 \mu \mathrm{m}$ & $\%$ & 5.74 \\
$500 \mu \mathrm{m} \geq \mathrm{CBP}$ & $\%$ & 80.15 \\
Processing loss & $\%$ & 1.35 \\
\hline
\end{tabular}

Value presented as mean \pm standard deviation; ${ }^{a}$ Weight percentage on dry basis; ${ }^{b}$ Weight percentage on dry ash free basis; ${ }^{c}$ CBP stands for corncob biochar particle.

There were various sizes of biochar particles in the corncob biochar, and more than $80 \%$ of the particles were smaller than $500 \mu \mathrm{m}$ (Table 2). Although biochar particle size distribution did not show any effect on the toxic effect of the biochar [51], a smaller particle size could increase the surface area and water holding capacity. The proximate analysis of biochar indicated that there was $14.48 \%$ and $78.98 \%$ of VM and FC, respectively (Table 2). These results were in agreement with the results in the previous study [6]. It was reported that the AC, VM, and FC were 1.2-71.8\%, 14.9-34.9\%, and 36.4-85.0\%, respectively, in various biochars produced via slow pyrolysis process at $450{ }^{\circ} \mathrm{C}$ using different feedstocks [6,52]. The VM of the biochar in this study was $14.48 \%$, which was below the threshold of VM of biochar for soil application (20\%) [53]. This implied that a self-purging pyrolysis reactor was able to produce biochar with an acceptable amount of volatile matter. The $\mathrm{AC}$ and $\mathrm{pH}$ value of the biochar in the present study were also in agreement with the results from previous studies [6,33,52]. The biochar had a mean $\mathrm{pH}$ value of 10.34, which indicated a high alkalinity. The alkalinity generally results from the salts present in the ash. The high $\mathrm{pH}$ value of biochar might be a result of the high $\mathrm{K}$ content $(25,602 \mathrm{mg} / \mathrm{kg})$ in the biochar [54], which was the highest elemental content in the corncob biochar. Salt stress on plants might be exposed by the high AC of the biochar [38]. Biochar with a high $\mathrm{pH}$ could be applied to soils that need a liming effect [55]. However, the negative impacts of salt stress on seed germination were reported in previous studies [38,56]. Hoekstra et al. [35] reported that salinity might negatively affect germination and plant growth, especially at the early stage of the germination period. Generally, the effects of the salt stress were irrelevant in biochar water extract with an EC value of $\leq 2.0 \mathrm{mS} / \mathrm{cm}$ [35]. The EC value of the biochar was $7.21 \mathrm{mS} / \mathrm{cm}$ as shown 
in Table 2, thus the negative effects of the salt stress on germination and seedling growth could not be disregarded in this study.

The results of the mineral content, trace element content, ultimate analysis, and cation exchange capacity of biochar are described in Tables 3 and 4. The major mineral contents in the biochar were $\mathrm{K}, \mathrm{P}, \mathrm{Mg}, \mathrm{Ca}, \mathrm{Zn}, \mathrm{Na}, \mathrm{Mn}, \mathrm{Fe}$, and $\mathrm{Al}$, respectively. Consequently, the analysis of the effective cation exchange capacity showed the highest exchangeable $\mathrm{K}^{+}$of $62.7 \mathrm{cmol}_{\mathcal{c}} / \mathrm{kg}$. The ECEC was $71.1 \mathrm{cmol}_{\mathcal{c}} / \mathrm{kg}$. The addition of biochar to soils has a potential to enhance the soil cation exchange capacity, as reported in a previous study [57]. The major heavy metals in the biochar were $\mathrm{Zn}, \mathrm{Mn}, \mathrm{Fe}, \mathrm{Cu}, \mathrm{Cr}, \mathrm{Ni}, \mathrm{Pb}, \mathrm{As}, \mathrm{Cd}$, and $\mathrm{Co}$, respectively. The content of the heavy metals was less than $52.9 \mathrm{mg} / \mathrm{kg}$. In this study, the heavy metal content $(\mathrm{Zn}, \mathrm{Fe}, \mathrm{Cu}, \mathrm{Cr}, \mathrm{Pb}$, and $\mathrm{Cd}$ ) in biochar was relatively low compared to the results (up to $214.05 \mathrm{mg} / \mathrm{kg}$ ) from rice straw, wheat straw, and corn stalk biochar in previous studies [25,58]. The ultimate analysis indicated that the biochar had a high C (77.6\%), but low $\mathrm{N}$ content $(65.21 \%)$. This resulted in a high $\mathrm{C} / \mathrm{N}$ ratio (65.21), which could lead to a short-term $\mathrm{N}$ immobilization after incorporating biochar into soils [59]. Based on the elemental properties of the corncob biochar, it was observed that the biochar had the potential to provide additional macronutrients such as $\mathrm{K}, \mathrm{P}, \mathrm{C}, \mathrm{N}$, $\mathrm{Mg}$, and $\mathrm{Ca}$ to plants. In addition, micronutrients such as $\mathrm{Zn}, \mathrm{Na}, \mathrm{Fe}, \mathrm{Mn}$, and $\mathrm{Cu}$ could have positive effects on plant growth, especially when biochar was applied in small quantities [25].

Table 3. Major mineral content, trace element content and ultimate analysis of corncob biomass and biochar.

\begin{tabular}{|c|c|c|}
\hline Element & Biomass & Biochar \\
\hline \multicolumn{3}{|c|}{ Mineral content $(\mathrm{mg} / \mathrm{kg})^{\mathrm{a}}$} \\
\hline $\mathrm{Al}$ & 97.5 & 6.00 \\
\hline $\mathrm{Ca}$ & 285 & 787 \\
\hline $\mathrm{Fe}$ & 61.9 & 20.5 \\
\hline $\mathrm{K}$ & 6.38 & 25,602 \\
\hline $\mathrm{Mg}$ & 373 & 1268 \\
\hline Mn & 8.00 & 22.1 \\
\hline $\mathrm{Na}$ & 18.9 & 33.7 \\
\hline $\mathrm{P}$ & 430 & 2930 \\
\hline \multirow{2}{*}{\multicolumn{3}{|c|}{ Trace element $(\mathrm{mg} / \mathrm{kg})^{\mathrm{a}}$}} \\
\hline & & \\
\hline As & $<0.100$ & $<0.0500$ \\
\hline $\mathrm{Cd}$ & $<0.150$ & 0.0300 \\
\hline Co & $<0.150$ & 0.0100 \\
\hline $\mathrm{Cr}$ & 8.42 & 1.77 \\
\hline $\mathrm{Cu}$ & 5.81 & 9.32 \\
\hline $\mathrm{Ni}$ & 2.61 & $<0.150$ \\
\hline $\mathrm{Pb}$ & 0.500 & 0.0600 \\
\hline $\mathrm{Rb}$ & 0.970 & 21.4 \\
\hline $\mathrm{Sr}$ & 1.06 & 2.06 \\
\hline \multicolumn{3}{|c|}{ Ultimate analysis (wt. \%) b } \\
\hline C & 45.7 & 77.6 \\
\hline $\mathrm{N}$ & 0.611 & 1.19 \\
\hline S & 0.0580 & $<0.100$ \\
\hline $\mathrm{C} / \mathrm{N}$ & 74.8 & 65.2 \\
\hline
\end{tabular}

Table 4. Exchangeable cations and effective cation exchange capacity (ECEC) of corncob biochar.

\begin{tabular}{cc}
\hline Exchangeable Cations & Concentrations $\left(\mathbf{c m o l}_{\mathbf{c}} / \mathbf{k g}\right)$ \\
\hline $\mathrm{Al}^{3+}$ & 0 \\
$\mathrm{Ca}^{2+}$ & 1.80 \\
$\mathrm{Fe}^{3+}$ & 0 \\
$\mathrm{~K}^{+}$ & 62.7 \\
$\mathrm{Mg}^{2+}$ & 6.60 \\
$\mathrm{Mn}^{2+}$ & 0 \\
$\mathrm{Na}^{+}$ & 0 \\
$\mathrm{ECEC}$ & 71.1 \\
\hline
\end{tabular}




\subsection{Effects of Corncob Biochar on Cress Seed Germination}

The germination rates $\left(\mathrm{GR}_{24}\right.$ and $\left.\mathrm{GR}_{48}\right)$ are shown in Figure 1. At a biochar application rate of $10 \mathrm{t} / \mathrm{ha}$, biochar treatments did not have a significant effect $(p=0.4750)$ on the $\mathrm{GR}_{48}$. All of the biochar treatments $(\mathrm{FB}, \mathrm{DB}, \mathrm{WB}$, and $\mathrm{WE})$ resulted in similar germination rates $\left(\mathrm{GR}_{48}\right)$ as in the $\mathrm{CON}$. In case of $\mathrm{GR}_{24}$, it was observed that the biochar treatments also did not significantly delay $(p=0.9191)$ the germination of cress seeds. Therefore, FB, DB, WB, WE, and CON showed similar values of $\mathrm{GR}_{24}$. This result implied that a biochar application rate of $10 \mathrm{t} /$ ha or lower did not significantly reduce the germination rate of cress. At an application rate of $20 \mathrm{t} / \mathrm{ha}$, biochar treatments had a significant effect $(p=0.0335)$ on the $\mathrm{GR}_{48}$. The CON had the highest $\mathrm{GR}_{48}$ of $95 \%$ followed by WB (93\%). It was observed from $\mathrm{GR}_{24}$ that the biochar treatments had a significant impact $(p=0.0216)$ on cress germination. Compared to the $\mathrm{CON}, \mathrm{FB}$, and $\mathrm{WE}$ reduced $\mathrm{GR}_{24}$, while $\mathrm{DB}$ and $\mathrm{WB}$ increased $\mathrm{GR}_{24}$. It was evident that $\mathrm{WB}$ performed as good as $\mathrm{CON}$ on $\mathrm{GR}_{48}$ and even better than $\mathrm{CON}$ on $\mathrm{GR}_{24}$, which indicated that washing biochar successfully reduced its toxicity at an application rate of $20 \mathrm{t} / \mathrm{ha}$. At an application rate of $30 \mathrm{t} / \mathrm{ha}$, the effect of biochar treatments on $\mathrm{GR}_{48}$ was significant with $p$-values of $<0.0001$ but was not significant for $\mathrm{GR}_{24}(p=0.1105)$. FB and WE completely inhibited the germination of cress after $24 \mathrm{~h}\left(\mathrm{GR}_{24}=0 \%\right)$. The $\mathrm{GR}_{48}$ in WB treatments was not significantly different compared to the value in the CON. CON and DB treatments were significantly different $(p<0.05)$ with a $\mathrm{GR}_{48}$ of 95 and $73 \%$.

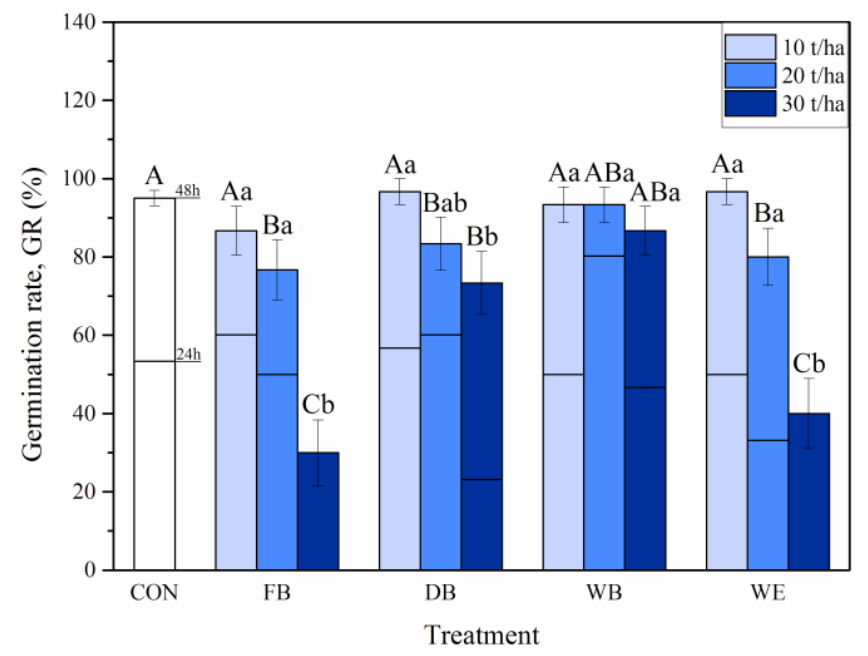

Figure 1. Germination rates (GR) under different biochar application rates (10, 20, and $30 \mathrm{t} / \mathrm{ha})$ and treatments (Control: CON, Fresh biochar: FB, Dried biochar: DB, Washed biochar: WB and Biochar water extract: WE). The first stacked column indicates the germination rate after $24 \mathrm{~h}\left(\mathrm{GR}_{24}\right)$, while the second stacked column shows the germination rate between $24-48 \mathrm{~h}$. The sum of stacked columns represents the germination rate after $48 \mathrm{~h}\left(\mathrm{GR}_{48}\right)$ Different capital letters show significant differences in $\mathrm{GR}_{48}$ between biochar treatments at same application rate $(p<0.05)$, and different small letters show significant differences in $\mathrm{GR}_{48}$ between biochar application rates of same biochar treatment $(p<0.05)$. Standard errors of $\mathrm{GR}_{48}$ are represented by the bars ( $n=6$ for the treatments, and $n=24$ for the CON).

The application rate of biochar had a significant effect on $\mathrm{GR}_{48}$ in $\mathrm{FB}$ and WE treatments with $p$-values of $<0.0018$, and 0.0033 . This result was in agreement with the findings from previous research describing a significant influence of the biochar application rate on seed germination $[37,38,60]$. On the contrary, the application rate did not significantly impact the $\mathrm{GR}_{48}$ in $\mathrm{DB}(p=0.1267)$ and $\mathrm{WB}$ $(p=0.5986)$ treatments. This indicated that washing biochar did sufficiently reduce the toxicity even at an application rate of $30 \mathrm{t} / \mathrm{ha}$, when the germination rate was considered as an indicator. As shown in Figure 1, the germination rate $\left(\mathrm{GR}_{48}\right)$ was significantly different in $\mathrm{FB}$ and WE treatments with increasing application rates from 20 to $30 \mathrm{t} / \mathrm{ha}$, indicating a high toxicity in the fresh biochar and 
biochar water extract. While the application rate of biochar increased from 10 to $30 \mathrm{t} / \mathrm{ha}$, the $\mathrm{GR}_{48}$ decreased from 93 to 87,97 to 73,97 to 40 , and 87 to $30 \%$ in WB, DB, WE, and FB treatments, respectively. WB treatments showed the best performance in reducing biochar toxicity, when germination was used as an indicator. Apart from WB treatments, DB also showed a good potential to reduce the germination inhibition induced by biochar toxicity.

The germination rate can be considered as the most sensitive indicator for the toxicity in different biochar treatments, which was confirmed by a previous study [33]. Based on the results of this study, corncob biochar could be used at a low application rate $(10 \mathrm{t} / \mathrm{ha})$ without a significant phytotoxic effect on seed germination. In a previous study, it was reported that biochar from date palm leaflets did not result in toxic effect on lettuce germination [61]. It was reported that the addition of biochar at low application rates (10-50 t/ha) increased germination of wheat [60]. At an application rate of more than $20 \mathrm{t} / \mathrm{ha}$, biochar treatments have to be applied to reduce the phytotoxicity in biochar and negative effects on germination. Washing and heat treatment of biochar showed promising results in reducing negative effects of biochar on seed germination. FB and WE showed acute and severe toxic effects on germination. A strong negative effect of WE on germination was also reported by Buss and Mašek [33]. Therefore, after washing corncob biochar, the biochar water extract must be managed properly to avoid contamination to the environment. Water-soluble toxic substances such as PAHs, phenols, organic acids, ketones, and alcohols in WE can result in high phytotoxicity on seed germination [62]. In the FB treatments, cress seeds were in direct contact with biochar and were also exposed to water-soluble compounds and volatiles. Therefore, FB resulted in high levels of toxicity on seed germination. In this study, the germination test was carried out in closed mini greenhouses, therefore the seeds were fully exposed to volatiles. These volatiles accumulate in the air, which could inhibit the germination without direct contact to cress seeds. It was reported that the germination of spring barley decreased due to the volatiles released from hydrochar [37]. Volatile toxic substances in biochar also demonstrated negative effects on germination, which resulted in a delayed germination in cress [33]. A pH value of 5.5-7.5 was found to be preferable for seed germination [63]. The high pH value (10.34) of the biochar might be responsible for germination inhibition [54]. In addition, the high AC in biochar could also induce salt stress, which might also have reduced the germination rate. It was suggested that water-soluble compounds in biochar could have played a predominant role in biochar phytotoxicity [27]. In the FB, DB, and WB treatments, biochar was mixed with water, in which toxic substances could have been released. Therefore, there was a high risk of germination inhibition by the water-soluble compounds.

\subsection{Effects of Corncob Biochar on Shoot Length}

Figure 2 shows the effect of biochar treatments and application rates on the shoot length. At a biochar application rate of $10 \mathrm{t} / \mathrm{ha}$, biochar treatments had a highly significant effect $(p<0.0001)$ on the shoot length. The CON had the highest shoot length of $33.01 \mathrm{~mm}$. Among the treatments, the shoot length was highest in WB $(23.28 \mathrm{~mm})$, but it was not significantly higher than the shoot length in DB. On the other hand, FB and WE significantly reduced the shoot length compared to DB and WB. At a biochar application rate of $20 \mathrm{t} / \mathrm{ha}$, the effect of biochar treatments on the shoot length was also highly significant $(p<0.0001)$. In $\mathrm{WB}$, the shoot length $(21.90 \mathrm{~mm})$ increased significantly compared to $\mathrm{FB}, \mathrm{DB}$, and WE. As expected, the lowest shoot length was found in FB $(7.93 \mathrm{~mm})$. However, the shoot lengths among FB, DB, and WE treatments were not significantly different. This implies that the phytotoxic effect on the shoot length was significantly reduced by washing the biochar. In case of an application rate of $30 \mathrm{t} / \mathrm{ha}$, biochar treatments also had a significant impact $(p<0.0001)$ on the shoot length. WB treatment showed the highest potential in reducing the phytotoxicity, which resulted in significantly higher shoot lengths $(11.57 \mathrm{~mm})$ compared to the other biochar treatments (FB, DB, and WE). This indicated that at a high application rate washing biochar with de-ionized water could still reduce the phytotoxicity to some extent. 


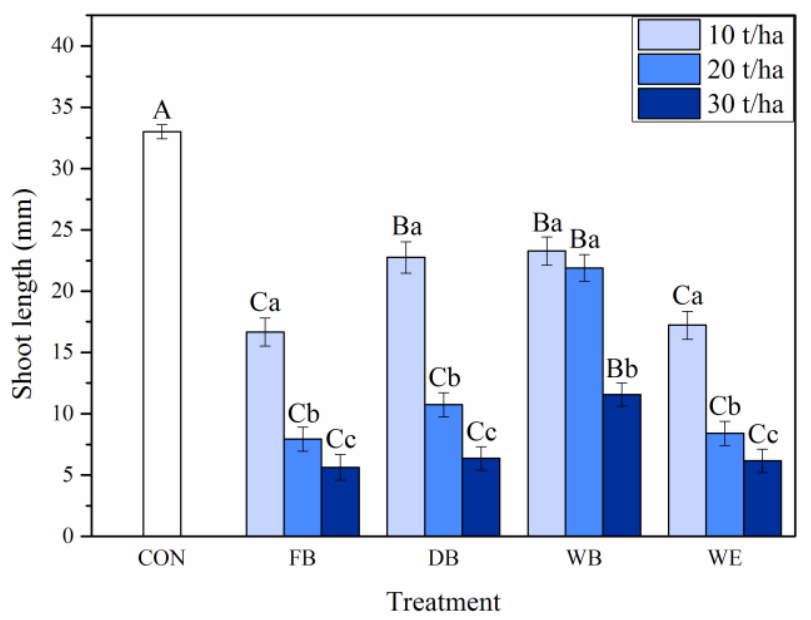

Figure 2. Shoot length of cress under different biochar application rates (10, 20, and $30 \mathrm{t} / \mathrm{ha})$ and treatments (Control: CON, Fresh biochar: FB, Dried biochar: DB, Washed biochar: WB and Biochar water extract: WE). Different capital letters show significant differences between biochar treatments at same application rate $(p<0.05)$, and different small letters show significant differences between biochar application rates of same biochar treatment $(p<0.05)$. Standard errors are represented by the bars $(\mathrm{n}=6$ for the treatments, and $n=24$ for the $\mathrm{CON}$ ).

The effect of biochar application rates on the shoot length was highly significant $(p<0.0001)$ in all of the biochar treatments $(\mathrm{FB}, \mathrm{DB}, \mathrm{WB}$, and $\mathrm{WE})$, which was in agreement with the results from a previous study [25]. The shoot length decreased significantly with increasing application rates from 10-20 and 20-30 t/ha in FB, DB, and WE. It should be noted, that increasing application rates from 10-20 t/ha did not significantly reduce the shoot length in WB (only $6 \%$ reduction). However, increasing the application rate from $20-30 \mathrm{t} /$ ha resulted in a significant reduction $(51 \%)$ of the shoot length in WB treatments.

The shoot length was found to be mainly affected by the delayed germination [33]. The delayed germination reduced the time for plant growth, which might result in reduced shoot lengths. The shoot length proved to be a good indicator to evaluate the effect of biochar treatments and application rates. This could be supported by the fact that all of the treatments and application rates showed significant differences in the shoot lengths compared to the CON. The shoot length was significantly reduced by the addition of biochar produced from peanut hull at $500{ }^{\circ} \mathrm{C}$ [38]. Contrarily, it was reported that biochar derived from date palm leaflets promoted the shoot length of lettuce [61]. However, the germination test in the previous study was carried out on filter papers, which could lead to the different outcomes compared to the germination test on biochar-sand mixtures in our study. The strong negative effect of WE treatments on the shoot length was supported by similar findings from a previous research, where rice straw biochar significantly reduced the shoot length of corn, rice, and wheat [25].

\subsection{Effects of Corncob Biochar on Shoot Fresh Weight}

The effect of biochar treatments on shoot fresh weight is illustrated in Figure 3. The biochar treatments had a significant impact $(p<0.0001)$ on shoot fresh weight in all biochar application rates $(10,20$, and $30 \mathrm{t} / \mathrm{ha})$. At a biochar application rate of $10 \mathrm{t} / \mathrm{ha}$, the DB and WB treatments resulted in similar shoot fresh weight compared to the CON. The FB had the most negative effect on the shoot fresh weight among the treatments. The WB treatment still showed the highest shoot fresh weight among the biochar treatments at an application rate of $20 \mathrm{t} / \mathrm{ha}$, but was significantly reduced compared to the $C O N$. The FB, DB, and WE had significantly lower shoot fresh weights than that of WB. In CON, WB, DB, WE, and FB treatments, the shoot fresh weight was 0.054, 0.050, 0.032, 0.027, and $0.027 \mathrm{~g}$, respectively. At a $30 \mathrm{t} / \mathrm{ha}$ application rate, there was a significant reduction of the shoot fresh weight 
in the WB compared to the CON $(0.054 \mathrm{~g})$. However, the shoot fresh weight in the WB $(0.032 \mathrm{~g})$ was significantly higher than in the $\mathrm{FB}, \mathrm{DB}$, and $\mathrm{WE}$ treatments. The FB, $\mathrm{DB}$, and WE treatments resulted in a similar shoot fresh weight of $0.011-0.014 \mathrm{~g}$.

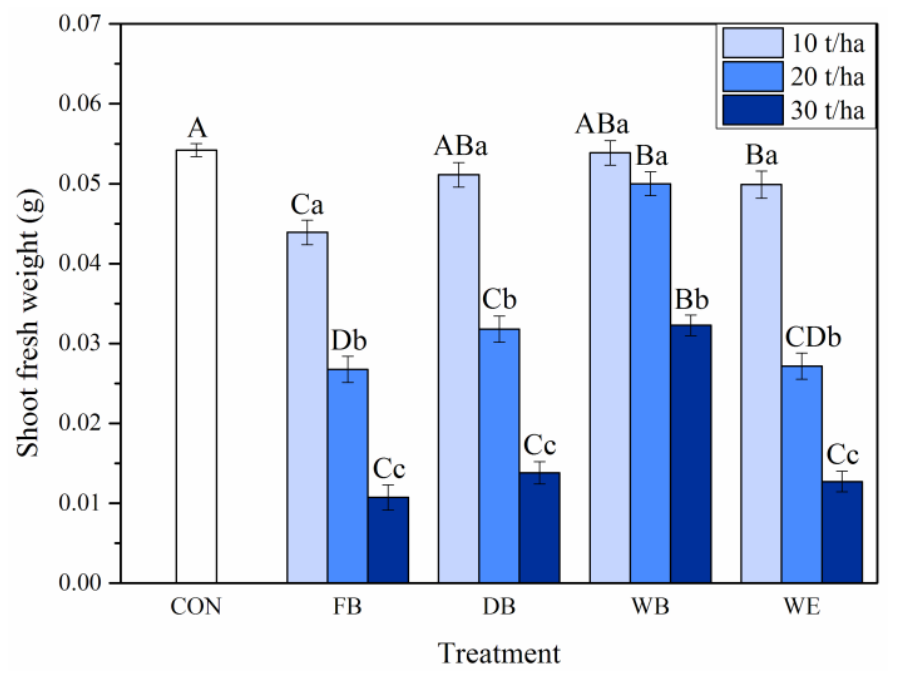

Figure 3. Shoot fresh weight of cress under different biochar application rates (10, 20, and $30 \mathrm{t} / \mathrm{ha}$ ) and treatments (Control: CON, Fresh biochar: FB, Dried biochar: DB, Washed biochar: WB and Biochar water extract: WE). Different capital letters show significant differences between biochar treatments at same application rate $(p<0.05)$, and different small letters show significant differences between biochar application rates of same biochar treatment $(p<0.05)$. Standard errors are represented by the bars $(\mathrm{n}=6$ for the treatments, and $\mathrm{n}=24$ for the $\mathrm{CON}$ ).

The biochar application rate significantly influenced $(p<0.0001)$ the shoot fresh weight in all biochar treatments, including FB, DB, WB, and WE. The reduction of the shoot fresh weight was highly significant (about 50\% reduction) with increasing application rates from 10 to 20 and 20 to $30 \mathrm{t} / \mathrm{ha}$ in FB, DB, and WE treatments. The shoot fresh weight was not significantly reduced (only $7 \%$ reduction), when the application rate increased from 10 to $20 \mathrm{t} / \mathrm{ha}$ in WB treatments. This result indicated that washing biochar could adequately reduce the phytotoxic effect on shoot fresh weight up to an application rate of $20 \mathrm{t} / \mathrm{h}$. However, at an application rate of $30 \mathrm{t} / \mathrm{ha}$ the shoot fresh weight was significantly reduced by $36 \%$. In general, the WB treatments showed the highest shoot fresh weight among the biochar treatments for every application rate investigated in this study.

Contrary to the findings in our study, it was determined that adding corncob biochar significantly increased the fresh weight of wheat in sandy soil [64]. A previous study also showed that biochar derived from argan shells increased fresh biomass weight of salad and barley [65]. In addition, it was reported that peanut hull biochar did not have a significant influence on the fresh weight of barley after germination [38]. In agreement with the results in our study, peanut hull biochar significantly reduced the fresh weight of cress seedlings, when the seeds were germinated without extra irrigation [38]. This implied that biochar from different feedstocks and pyrolysis conditions could have various effects on seed germination and seedling growth [54]. Therefore, potential toxic effects of each biochar need to be determined before its application in agriculture.

\subsection{Effects of Corncob Biochar on Dry Matter Content of the Shoot Biomass}

Figure 4 describes the treatment and application rate effect of biochar on the dry matter content of the shoot biomass. The treatment effect was highly significant $(p<0.0001)$ for all biochar application rates. At a biochar application rate of $10 \mathrm{t} / \mathrm{ha}$, the FB treatment had a significantly higher DM than other treatments and the $\mathrm{CON}$, while the $\mathrm{CON}, \mathrm{DB}, \mathrm{WB}$, and WE had comparable DM contents. At a $20 \mathrm{t} /$ ha application rate, FB and WE performed significantly better than other treatments and 
the CON, which resulted in DM contents of 35.34 and $34.46 \%$, respectively. At a $30 \mathrm{t} /$ ha application rate, the $\mathrm{FB}, \mathrm{DB}$, and WE had comparable DM contents, which were significantly higher than the DM content in the WB and CON. The DM content in FB, WE, DB, WB, and CON was 37.37, 35.82, 35.35, 29.48 , and $21.10 \%$, respectively. It should be noted that for all application rates the CON had the lowest DM content compared to the biochar treatments.

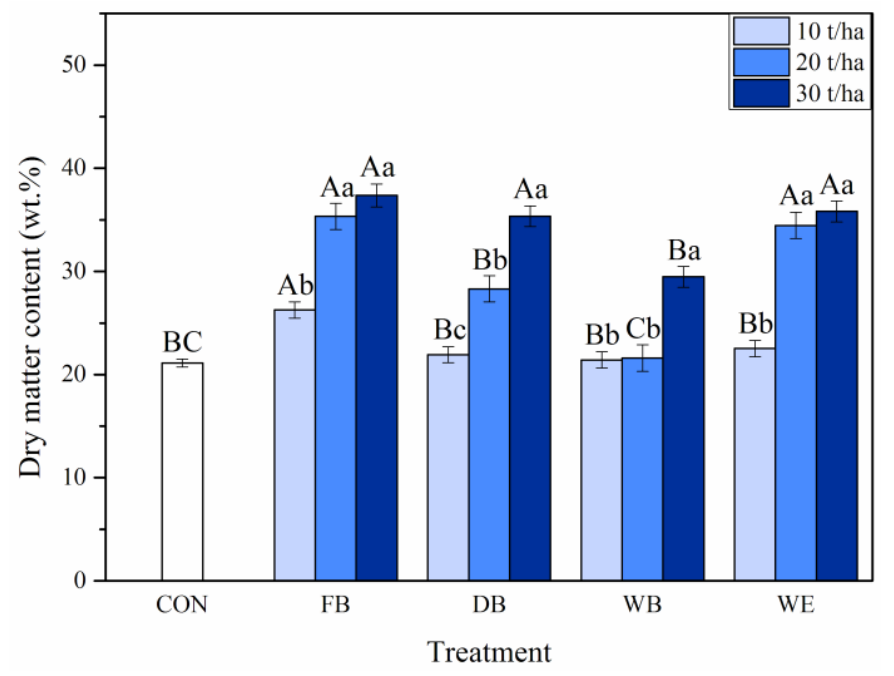

Figure 4. Dry matter content of the shoot biomass under different biochar application rates (10, 20, and $30 \mathrm{t} / \mathrm{ha}$ ) and treatments (Control: CON, Fresh biochar: FB, Dried biochar: DB, Washed biochar: WB and Biochar water extract: WE). Different capital letters show significant differences between biochar treatments at same application rate $(p<0.05)$, and different small letters show significant differences between biochar application rates of same biochar treatment $(p<0.05)$. Standard errors are represented by the bars ( $n=6$ for the treatments, and $n=24$ for the $C O N$ ).

It was determined that the biochar application rate had a significant impact on the DM content in all biochar treatments. The $p$-values were $\leq 0.0004$. In the FB treatment, the DM content did not increase significantly, when the application rate increased from 20 to $30 \mathrm{t} / \mathrm{ha}$. This might be due to the phytotoxic effect at high application rates in FB treatments. In DB treatments, the DM content significantly increased with increasing biochar application rates. Only the DM content at $30 \mathrm{t} / \mathrm{ha}$ was significantly higher than the other application rates in WB treatments. The DM content in WB treatments increased by 0.17 and $7.89 \%$ with increasing application rates from 10 to 20 and 20 to $30 \mathrm{t} / \mathrm{ha}$, respectively. In case of WE treatments, the DM content did not significantly increase with increasing application rates of 20 to $30 \mathrm{t} / \mathrm{ha}$, which could be explained by a high phytotoxic effect at high application rates. Among the biochar treatments, WB had the lowest DM content. This implies that the $\mathrm{DM}$ content could be promoted by the mineral nutrients. Since the nutrients leached away in the WB treatment, the DM content of the shoot biomass was negatively affected by the nutrient deficiency.

In general, the DM content of shoot biomass increased in biochar treatments compared to the CON. A positive effect of biochar on shoot dry weight was also reported in a previous study [66]. This can be explained by the addition of mineral nutrients from biochar ash [67]. Water extract from corn stover biochar was also found to increase the shoot dry weight of tomato seedlings [68].

\subsection{Phytotoxic Compounds in Biochar}

There was only a limited amount of research on the phytotoxic effects of biochar. It was reported that various phytotoxic compounds were responsible for the negative effects on germination and seedling growth. Conventional toxic compounds in biochar include toxic metals, tars, PAH, furans, and dioxins $[23,24]$. Leachable organic compounds in biochar were found to have negative effects on soil, plants, and the environment [27]. In addition, other potential toxic compounds in biochar were 
free radicals, which were generated during a pyrolysis process. Negative effects on seed germination, such as germination inhibition and delayed shoot growth were observed in biochar with ample free radicals [25]. A previous study carried out by Liao et al. [25] showed that heavy metals and PAHs had less negative impacts on seed germination compared to the free radicals. It was found that mobile organic compounds in biochar resulted in high phytotoxic effects on cress seed germination, and shoot and root length, while PAHs in biochar might not be responsible for the toxicity on seed germination, since the mobility of the PAHs was relatively low [33]. Furthermore, salt stress and water-soluble toxic organic compounds could lead to high toxic effects on seed germination [56]. Therefore, one or a few of the above-mentioned elements could have a negative effect on germination and seedling growth in cress. Further research is needed to identify the phytotoxic substances in biochar from a self-purging pyrolysis reactor in order to ensure a safe and sustainable application in agriculture.

\subsection{Effects of Biochar Treatments and Application Rates}

A significant negative effect of FB treatments on germination was identified in cress. The negative impact on the germination rate drastically increased with increasing application rates. Therefore, the raw corncob biochar should be tested for its phytotoxicity and treated to reduce the toxicity. As shown in Figure 4, the shoot biomass in FB treatments had the highest DM content (i.e., the lowest MC). This might be explained by the positive effect of nutrients in FB on the biomass production, which led to a high DM content. The high level of water-soluble toxic compounds in FB might also damage the plasma membrane of cress cells, which reduced the water uptake ability of cress seedlings resulting in a low MC in the shoot biomass. It was reported that a direct contact of FB with seeds intensified the phytotoxic effect of biochar [33]. Nevertheless, it was observed that FB showed some positive effects on the dry matter content of the shoot biomass, which might be associated with the additional $\mathrm{P}$ and $\mathrm{K}$ from biochar. In the present study, high amounts of $\mathrm{K}$ and $\mathrm{P}$ were identified in the corncob biochar. Moreover, the effective cation exchange capacity of $\mathrm{K}^{+}$was also considerably high, which could lead to a better retention capacity of the cation against leaching. FB was hydrophobic and had a lower capacity to absorb water. The hydrophobicity of FB could be reduced by an aging and weathering process $[69,70]$. A short-term application in this study showed, that FB had a negative effect on germination rate, shoot length, and shoot fresh weight, but the results might be different in a long-term application. In general, the most significant phytotoxic effect on the germination and seedling growth of cress was observed in FB treatments. This could be associated with the low water holding capacity and the high phytotoxicity in FB treatments. The results of FB treatments in this study were in agreement with the findings from a previous study, where the effect of FB suspension was studied [16]. Therefore, it is necessary to perform biochar aging and weathering treatments such as washing and heat treatment to reduce the phytotoxicity.

The WE treatments showed a less negative impact on the germination rate and seedling growth of cress compared to the FB treatments. The germination rate, shoot length, and shoot fresh weight decreased sharply with increasing biochar application rates, while the dry matter content increased. In a previous study, the negative effect of the water extract from macadamia nut shell biochar produced at $430{ }^{\circ} \mathrm{C}$ on the germination of radish and corn seeds was identified [59]. The water extract of biochars from varying feedstocks was found to reduce seedling growth in corn [39]. A negative effect of water extract from pine biochar produced at $450{ }^{\circ} \mathrm{C}$ was also observed on the growth of aquatic photosynthetic microorganisms [27]. Water-soluble toxic compounds in biochar were found to reduce the germination rate in cress [33]. Rombolà et al. [16] reported that the germination rate of cress in biochar water extract was similar to that of fresh biochar suspensions, which was in agreement with the findings in our study. It was evident that the water-soluble phytotoxic compounds decreased the germination rate and shoot growth in cress. Therefore, after washing biochar the water extract generated from this process must be handled with care and disposed of properly without contaminating the environment. Future research could be carried out to identify the methods to eliminate the toxicity in the water extract and its potential uses. 
It was reported that the phytotoxicity in biochar could be reduced by handling, processing, and storage [33]. The initial property of biochar could be changed from hydrophobic to hydrophilic by heat treatment. The reduction of VOCs in biochar can also be achieved by heat treatment. Nevertheless, the drying process might not be able to eliminate all of the water-soluble toxic substances in biochar. Therefore, there might be less phytotoxicity in DB treatments, but some toxic compounds still remain. In comparison, DB treatments should have higher water holding capacity and lower phytotoxicity than FB and WE treatments. The findings of this study indicated that the phytotoxicity in biochar was significantly reduced in the DB treatments at an application rate of $10 \mathrm{t} / \mathrm{ha}$. However, the DB treatments had a slightly higher shoot length and shoot fresh weight than FB and WE treatments. It was reported in a recent study that drying of biochar for $24 \mathrm{~h}$ at different temperatures ranging from 100 to $300{ }^{\circ} \mathrm{C}$ significantly reduced the phytotoxicity [41]. In our study, a drying temperature of $105( \pm 2){ }^{\circ} \mathrm{C}$ might not be sufficient to remove all of the volatile matters in the biochar. It was reported that drying biochar at $100{ }^{\circ} \mathrm{C}$ for $24 \mathrm{~h}$ reduced PAHs by 33.8-88.1\% [41].

The WB treatment showed the best result for the germination rate, shoot length, and shoot fresh weight of cress. This implied that washing biochar had the best performance in reducing biochar phytotoxicity. Water-soluble toxic compounds were leached away after washing the biochar with de-ionized water. This result was in agreement with the findings from previous studies stating that the phytotoxicity was significantly reduced by washing biochar with water or an organic solvent $[37,39]$. The amount of VOCs in biochar was also reduced by repeated leaching [33]. It was evident that washing biochar sufficiently mitigated negative effects of biochar phytotoxicity on plant growth [71]. Rombolà et al. [16] also reported that biochar washed with ethanol showed a better performance than FB and WE on the seed germination of cress. It was found that the volatile matters in biochar did not have a significant toxic effect in a gas exchangeable environment, but they could lead to high toxicity in a closed environment $[33,37]$ like the condition of the mini greenhouses in our study. Therefore, it can be expected that the WB treatments could have a better performance in unsealed environment.

According to the results in this study, the germination rate, shoot length, shoot fresh weight, and dry matter content of the shoot biomass proved to be sensitive indicators of the cress response to phytotoxic substances in biochar. These indicators were significantly influenced by the biochar application rate, especially at the application rate of $30 \mathrm{t} / \mathrm{ha}$ or higher. It was also reported in previous studies that the biochar application rate had a significant impact on germination and seedling growth $[25,68]$. Therefore, it is very important to identify suitable application rates of biochar for various agricultural applications.

In this study, low-cost equipment for germination tests was used to identify the phytotoxic effects of biochar on seed germination. The results indicated that the equipment and settings were suitable to effectively identify the phytotoxic effects of different biochar treatments and application rates. Future research on the phytotoxicity of biochar should focus on the effect of biochar on the root biomass, which will increase the knowledge of biochar-root interactions.

\section{Conclusions}

Significant phytotoxic effects of biochar on the germination rate, shoot length, shoot fresh weight, and shoot dry matter content of cress were identified. Untreated corncob biochar (FB) and the WE showed severe toxic effects, revealing high soil and environmental risks, while the DB and WB showed less toxicity. The observed order of performance of the biochar treatments for germination, shoot length, and shoot fresh weight at every biochar application rate investigated in this study was $\mathrm{WB}>\mathrm{DB}>\mathrm{WE}>\mathrm{FB}$. When the biochar application rate increased from 10 to $30 \mathrm{t} / \mathrm{ha}$, in the $\mathrm{WB}, \mathrm{DB}, \mathrm{WE}$, and FB treatments, the germination rate after $48 \mathrm{~h}\left(\mathrm{GR}_{48}\right)$ decreased by $7,23,57$, and $57 \%$, respectively. With increasing application rates from 10 to $30 \mathrm{t} / \mathrm{ha}$, the shoot fresh weight also decreased by 41, 72, 74 , and $75 \%$, in the WB, DB, WE, and FB treatments, respectively. It was concluded that washing (WB) was adequate to significantly reduce the phytotoxicity in biochar. However, the effective mitigation of the phytotoxicity by WB treatments was only confirmed up to a biochar application rate of $20 \mathrm{t} / \mathrm{ha}$. 
Simple heat treatment (DB) also significantly reduced the phytotoxicity, but only up to an application rate of $10 \mathrm{t} / \mathrm{ha}$. Therefore, the selection of an economical biochar treatment should depend on biochar properties, application rates, and specific requirements of the application. Based on the findings of this study, it can be concluded that washing and heat treatment are effective in reducing the phytotoxicity of the corncob biochar. Combining washing and heat treatments could further reduce the biochar toxicity.

Author Contributions: Conceptualization, K.I. and S.L.; Methodology, K.I., S.L. and M.S.I.; Software, K.I. and M.S.I.; Validation, K.I., S.L. and M.S.I.; Formal Analysis, K.I. and M.S.I.; Investigation, K.I. and M.S.I.; Resources, K.I., S.L. and J.M.; Data Curation, K.I. and M.S.I.; Writing-Original Draft Preparation, K.I.; Writing-Review and Editing, K.I., S.L. and J.M.; Visualization, K.I. and M.S.I.; Supervision, K.I., S.L. and J.M.; Project Administration, K.I. and S.L.; Funding Acquisition, K.I., S.L. and J.M.

Funding: This research was funded by the Food Security Center of the Universität Hohenheim, the foundation fiat panis, the German Academic Exchange Service (DAAD), the Federal Ministry of Economic Cooperation and Development (BMZ) and the German Federal Ministry of Education and Research (BMBF). This research is the result of the project BiomassWeb WP 5.1 (Project No. 031A258F). The APC was funded by the project BiomassWeb.

Acknowledgments: The authors gratefully thank Jens Hartung, University of Hohenheim, Institute of Crop Science, Biostatistics Group (340c) for his advice on the statistical analysis. The authors would like to thank Sabine Nugent for proofreading and language editing of this manuscript.

Conflicts of Interest: The authors declare no conflict of interest. The funders had no role in the design of the study; in the collection, analyses, or interpretation of data; in the writing of the manuscript, and in the decision to publish the results.

\section{References}

1. Liu, X.; Zhang, Y.; Li, Z.; Feng, R.; Zhang, Y. Characterization of corncob-derived biochar and pyrolysis kinetics in comparison with corn stalk and sawdust. Bioresour. Technol. 2014, 170, 76-82. [CrossRef] [PubMed]

2. Budai, A.; Wang, L.; Gronli, M.; Strand, L.T.; Antal, M.J.; Abiven, S.; Dieguez-Alonso, A.; Anca-Couce, A.; Rasse, D.P. Surface properties and chemical composition of corncob and miscanthus biochars: Effects of production temperature and method. J. Agric. Food Chem. 2014, 62, 3791-3799. [CrossRef] [PubMed]

3. Gebremedhin, B.; Fernandez-Rivera, S.; Hassena, M.; Mwangi, W.; Ahmed, S. Maize and Livestock: Their Inter-Linked Roles in Meeting Human Needs in Ethiopia; ILRI Publications: Nairobi, Kenya, 2007.

4. Hoover, B.K. Herbaceous perennial seed germination and seedling growth in biochar-amended propagation substrates. HortScience 2018, 53, 236-241. [CrossRef]

5. Dumroese, R.K.; Heiskanen, J.; Englund, K.; Tervahauta, A. Pelleted biochar: Chemical and physical properties show potential use as a substrate in container nurseries. Biomass Bioenergy 2011, 35, $2018-2027$. [CrossRef]

6. Ronsse, F.; van Hecke, S.; Dickinson, D.; Prins, W. Production and characterization of slow pyrolysis biochar: Influence of feedstock type and pyrolysis conditions. GCB Bioenergy 2013, 5, 104-115. [CrossRef]

7. Scholz, S.M.; Sembres, T.; Roberts, K.; Whitman, T.; Wilson, K.; Lehmann, J. Biochar Systems for Smallholders in Developing Countries: Leveraging Current Knowledge and Exploring Future Potential for Climate-Smart Agriculture; The World Bank: Washington, DC, USA, 2014.

8. Chen, T.; Liu, R.; Scott, N.R. Characterization of energy carriers obtained from the pyrolysis of white ash, switchgrass and corn stover - Biochar, syngas and bio-oil. Fuel Process. Technol. 2016, 142, 124-134. [CrossRef]

9. Meng, J.; Wang, L.; Liu, X.; Wu, J.; Brookes, P.C.; Xu, J. Physicochemical properties of biochar produced from aerobically composted swine manure and its potential use as an environmental amendment. Bioresour. Technol. 2013, 142, 641-646. [CrossRef] [PubMed]

10. Intani, K.; Latif, S.; Kabir, A.K.M.R.; Müller, J. Effect of self-purging pyrolysis on yield of biochar from maize cobs, husks and leaves. Bioresour. Technol. 2016, 218, 541-551. [CrossRef]

11. Intani, K.; Latif, S.; Cao, Z.; Müller, J. Characterisation of biochar from maize residues produced in a self-purging pyrolysis reactor. Bioresour. Technol. 2018, 265, 224-235. [CrossRef]

12. Pare, T.; Gregorich, E.G.; Dinel, H. Effects of stockpiled and composted manures on germination and initial growth of cress (Lepidium sativum). Biol. Agric. Hortic. 1997, 14, 1-11. [CrossRef]

13. Gehringer, M.M.; Kewada, V.; Coates, N.; Downing, T.G. The use of Lepidium sativum in a plant bioassay system for the detection of microcystin-LR. Toxicon 2003, 41, 871-876. [CrossRef] 
14. Moser, B.R.; Shah, S.N.; Winkler-moser, J.K.; Vaughn, S.F.; Evangelista, R.L. Composition and physical properties of cress ( Lepidium sativum L.) and field pennycress ( Thlaspi arvense L.) oils. Ind. Crops Prod. 2009, 30, 199-205. [CrossRef]

15. Diwakar, B.T.; Dutta, P.K.; Lokesh, B.R.; Naidu, K.A. Physicochemical properties of garden cress (lepidium sativum 1.) seed oil. JAOCS, J. Am. Oil Chem. Soc. 2010, 87, 539-548. [CrossRef]

16. Rombolà, A.G.; Marisi, G.; Torri, C.; Fabbri, D.; Buscaroli, A.; Ghidotti, M.; Hornung, A. Relationships between Chemical Characteristics and Phytotoxicity of Biochar from Poultry Litter Pyrolysis. J. Agric. Food Chem. 2015, 63, 6660-6667. [CrossRef] [PubMed]

17. Bezerra, J.; Turnhout, E.; Vasquez, I.M.; Rittl, T.F.; Arts, B.; Kuyper, T.W. The promises of the Amazonian soil: Shifts in discourses of Terra Preta and biochar. J. Environ. Policy Plan. 2016, 0, 1-13. [CrossRef]

18. Lehmann, J.; Rillig, M.C.; Thies, J.; Masiello, C.A.; Hockaday, W.C.; Crowley, D. Biochar effects on soil biota-A review. Soil Biol. Biochem. 2011, 43, 1812-1836. [CrossRef]

19. Lehmann, J.; Joseph, S. Biochar for Environmental Management: Science, Technology and Implementation, 2nd ed.; Routledge: Abingdon-on-Thames, UK, 2015; ISBN 9780415704151.

20. Wardle, D.; Nilsson, M.-C.; Zackrisson, O.; Lehmann, J.; Sohi, S. Comment on “Fire-Derived Charcoal Causes Loss of Forest Humus". Science 2008, 321, 1295. [CrossRef]

21. Sagrilo, E.; Rittl, T.F.; Hoffland, E.; Alves, B.J.R.; Mehl, H.U.; Kuyper, T.W. Rapid decomposition of traditionally produced biochar in an Oxisol under savannah in Northeastern Brazil. Geoderma Reg. 2015, 6, 1-6. [CrossRef]

22. Aller, M.F. Biochar properties: Transport, fate, and impact. Crit. Rev. Environ. Sci. Technol. 2016, 46, 1183-1296. [CrossRef]

23. Hale, S.E.; Lehmann, J.; Rutherford, D.; Zimmerman, A.R.; Bachmann, R.T.; Shitumbanuma, V.; O’Toole, A.; Sundqvist, K.L.; Arp, H.P.H.; Cornelissen, G. Quantifying the total and bioavailable polycyclic aromatic hydrocarbons and dioxins in biochars. Environ. Sci. Technol. 2012, 46, 2830-2838. [CrossRef]

24. Freddo, A.; Cai, C.; Reid, B.J. Environmental contextualisation of potential toxic elements and polycyclic aromatic hydrocarbons in biochar. Environ. Pollut. 2012, 171, 18-24. [CrossRef] [PubMed]

25. Liao, S.; Pan, B.; Li, H.; Zhang, D.; Xing, B. Detecting free radicals in biochars and determining their ability to inhibit the germination and growth of corn, wheat and rice seedlings. Environ. Sci. Technol. 2014, 48, 8581-8587. [CrossRef] [PubMed]

26. Oh, T.K.; Shinogi, Y.; Chikushi, J.; Lee, Y.H.; Choi, B. Effect of Aqueous Extract of Biochar on Germination and Seedling Growth of Lettuce (Lactuca sativa L.). J. Fac. Agric. Kyushu Univ. 2012, 57, 55-60.

27. Smith, C.R.; Buzan, E.M.; Lee, J.W. Potential impact of biochar water-extractable substances on environmental sustainability. ACS Sustain. Chem. Eng. 2013, 1, 118-126. [CrossRef]

28. Yang, H.; Kudo, S.; Hazeyama, S.; Norinaga, K.; Mašek, O.; Hayashi, J.I. Detailed analysis of residual volatiles in chars from the pyrolysis of biomass and lignite. Energy Fuels 2013, 27, 3209-3223. [CrossRef]

29. Spokas, K.A.; Novak, J.M.; Stewart, C.E.; Cantrell, K.B.; Uchimiya, M.; DuSaire, M.G.; Ro, K.S. Qualitative analysis of volatile organic compounds on biochar. Chemosphere 2011, 85, 869-882. [CrossRef] [PubMed]

30. Elad, Y.; Cytryn, E.; Meller Harel, Y.; Lew, B.; Graber, E.R. The biochar effect: Plant resistance to biotic stress. Phytopathol. Mediterr. 2011, 50, 335-349. [CrossRef]

31. Cordella, M.; Torri, C.; Adamiano, A.; Fabbri, D.; Barontini, F.; Cozzani, V. Bio-oils from biomass slow pyrolysis: A chemical and toxicological screening. J. Hazard. Mater. 2012, 231-232, 26-35. [CrossRef]

32. Sfetsas, T.; Michailof, C.; Lappas, A.; Li, Q.; Kneale, B. Qualitative and quantitative analysis of pyrolysis oil by gas chromatography with flame ionization detection and comprehensive two-dimensional gas chromatography with time-of-flight mass spectrometry. J. Chromatogr. A 2011, 1218, 3317-3325. [CrossRef]

33. Buss, W.; Mašek, O. Mobile organic compounds in biochar - A potential source ofcontamination - Phytotoxic effects on cress seed (Lepidiumsativum) germination. J. Environ. Manag. 2014, 137, 111-119. [CrossRef]

34. Fornes, F.; Belda, R.M. Acidification with nitric acid improves chemical characteristics and reduces phytotoxicity of alkaline chars. J. Environ. Manag. 2017, 191, 237-243. [CrossRef] [PubMed]

35. Hoekstra, N.J.; Bosker, T.; Lantinga, E.A. Effects of cattle dung from farms with different feeding strategies on germination and initial root growth of cress (Lepidium sativum L.). Agric. Ecosyst. Environ. 2002, 93, $189-196$. [CrossRef]

36. Buss, W.; Graham, M.C.; Shepherd, J.G.; Mašek, O. Suitability of marginal biomass-derived biochars for soil amendment. Sci. Total Environ. 2016, 547, 314-322. [CrossRef] [PubMed] 
37. Bargmann, I.; Rillig, M.C.C.; Buss, W.; Kruse, A.; Kuecke, M. Hydrochar and biochar effects on germination of spring barley. J. Agron. Crop Sci. 2013, 199, 360-373. [CrossRef]

38. Busch, D.; Kammann, C.; Grünhage, L.; Müller, C. Simple Biotoxicity Tests for Evaluation of Carbonaceous Soil Additives: Establishment and Reproducibility of Four Test Procedures. J. Environ. Qual. 2012, 41, 1023. [CrossRef] [PubMed]

39. Rogovska, N.; Laird, D.; Cruse, R.M.; Trabue, S.; Heaton, E. Germination Tests for Assessing Biochar Quality. J. Environ. Qual. 2012, 41, 1014. [CrossRef]

40. Spokas, K.A.; Cantrell, K.B.; Novak, J.M.; Archer, D.W.; Ippolito, J.A.; Collins, H.P.; Boateng, A.A.; Lima, I.M.; Lamb, M.C.; McAloon, A.J.; et al. Biochar: A Synthesis of Its Agronomic Impact beyond Carbon Sequestration. J. Environ. Qual. 2012, 41, 973. [CrossRef]

41. Kołtowski, M.; Oleszczuk, P. Toxicity of biochars after polycyclic aromatic hydrocarbons removal by thermal treatment. Ecol. Eng. 2015, 75, 79-85. [CrossRef]

42. DIN 51718. Testing of Solid Fuels-Determination of the Water Content and the Moisture of Analysis Sample; Deutsches Institut für Normung e.V., Ed.; Beuth Verlag GmbH: Berlin, Germany, 2002.

43. DIN 51720. Testing of Solid Fuels-Determination of Volatile Matter Content; Deutsches Institut für Normung e.V., Ed.; Beuth Verlag GmbH: Berlin, Germany, 2001.

44. DIN 51719. Testing of Solid Fuels—Solid Mineral Fuels-Determination of Ash Content; Deutsches Institut für Normung e.V., Ed.; Beuth Verlag GmbH: Berlin, Germany, 1997.

45. König, N.; Blum, U.; Symossek, F.; Bussian, B.; Ellinghaus, R.; Furtmann, K.; Gärtner, A.; Gutwasser, F.; Hauenstein, M.; Kiesling, G. Handbuch forstliche Analytik; Bundesministerium für Ernährung und Landwirtschaft: Bonn, Germany, 2005.

46. van Zwieten, L.; Kimber, S.; Morris, S.; Chan, K.Y.; Downie, A.; Rust, J.; Joseph, S.; Cowie, A. Effects of biochar from slow pyrolysis of papermill waste on agronomic performance and soil fertility. Plant Soil 2010, 327, 235-246. [CrossRef]

47. Buss, W.; Kammann, C.; Koyro, H.-W. Biochar Reduces Copper Toxicity in Willd. in a Sandy Soil. J. Environ. Qual. 2012, 41, 1157. [CrossRef]

48. Müller, K.; Tintelnot, S.; Leubner-Metzger, G. Endosperm-limited Brassicaceae Seed Germination: Abscisic Acid Inhibits Embryo-induced Endosperm Weakening of Lepidium sativum (cress) and Endosperm Rupture of Cress and Arabidopsis thaliana. Plant Cell Physiol. 2006, 47, 864-877. [CrossRef] [PubMed]

49. OECD. Test No. 208: Terrestrial Plant Test: Seedling Emergence and Seedling Growth Test; OECD Publishing: Paris, France, 2006.

50. Özçimen, D.; Ersoy-Meriçboyu, A. A study on the carbonization of grapeseed and chestnut shell. Fuel Process. Technol. 2008, 89, 1041-1046. [CrossRef]

51. Oleszczuk, P.; Rycaj, M.; Lehmann, J.; Cornelissen, G. Influence of activated carbon and biochar on phytotoxicity of air-dried sewage sludges to Lepidium sativum. Ecotoxicol. Environ. Saf. 2012, 80, 321-326. [CrossRef] [PubMed]

52. Crombie, K.; Mašek, O.; Sohi, S.P.; Brownsort, P.; Cross, A. The effect of pyrolysis conditions on biochar stability as determined by three methods. GCB Bioenergy 2013, 5, 122-131. [CrossRef]

53. Brewer, C.E.; Unger, R.; Schmidt-Rohr, K.; Brown, R.C. Criteria to Select Biochars for Field Studies based on Biochar Chemical Properties. Bioenergy Res. 2011, 4, 312-323. [CrossRef]

54. Buss, W.; Graham, M.C.; Shepherd, J.G.; Mašek, O. Risks and benefits of marginal biomass-derived biochars for plant growth. Sci. Total Environ. 2016, 569-570, 496-506. [CrossRef] [PubMed]

55. Mukome, F.N.D.; Zhang, X.; Silva, L.C.R.; Six, J.; Parikh, S.J. Use of chemical and physical characteristics to investigate trends in biochar feedstocks. J. Agric. Food Chem. 2013, 61, 2196-2204. [CrossRef]

56. Gell, K.; van Groenigen, J.W.; Cayuela, M.L. Residues of bioenergy production chains as soil amendments: Immediate and temporal phytotoxicity. J. Hazard. Mater. 2011, 186, 2017-2025. [CrossRef] [PubMed]

57. Zhao, B.; Xu, R.; Ma, F.; Li, Y.; Wang, L. Effects of biochars derived from chicken manure and rape straw on speciation and phytoavailability of $\mathrm{Cd}$ to maize in artificially contaminated loess soil. J. Environ. Manag. 2016, 184, 569-574. [CrossRef]

58. Shen, X.; Huang, D.-Y.; Ren, X.-F.; Zhu, H.-H.; Wang, S.; Xu, C.; He, Y.-B.; Luo, Z.-C.; Zhu, Q.-H. Phytoavailability of $\mathrm{Cd}$ and $\mathrm{Pb}$ in crop straw biochar-amended soil is related to the heavy metal content of both biochar and soil. J. Environ. Manag. 2016, 168, 245-251. [CrossRef] 
59. Deenik, J.L.; McClellan, T.; Uehara, G.; Antal, M.J.; Campbell, S.; Antal, M.J.; Sonia, C. Charcoal volatile matter content influences plant growth and soil nitrogen transformations. Soil Sci. Soc. Am. J. 2010, 74, 1259-1270. [CrossRef]

60. Solaiman, Z.M.; Murphy, D.V.; Abbott, L.K. Biochars influence seed germination and early growth of seedlings. Plant Soil 2012, 353, 273-287. [CrossRef]

61. Al-Wabel, M.I.; Rafique, M.I.; Ahmad, M.; Ahmad, M.; Hussain, A.; Usman, A.R.A. Pyrolytic and hydrothermal carbonization of date palm leaflets: Characteristics and ecotoxicological effects on seed germination of lettuce. Saudi J. Biol. Sci. 2018. [CrossRef]

62. Buss, W.; Mašek, O.; Graham, M.; Wüst, D. Inherent organic compounds in biochar-Their content, composition and potential toxic effects. J. Environ. Manag. 2015, 156, 150-157. [CrossRef]

63. Shoemaker, C.A.; Carlson, W.H. pH Affects Seed Germination of Eight Bedding Plant Species. HORTSCIENCE 1990, 25, 762-764.

64. Amin, A.E.-E.A.Z. Impact of Corn Cob Biochar on Potassium Status and Wheat Growth in a Calcareous Sandy Soil. Commun. Soil Sci. Plant Anal. 2016, 47, 2026-2033. [CrossRef]

65. Bouqbis, L.; Daoud, S.; Koyro, H.W.; Kammann, C.I.; Ainlhout, F.Z.; Harrouni, M.C. Phytotoxic effects of argan shell biochar on salad and barley germination. Agric. Nat. Resour. 2017, 51, 247-252. [CrossRef]

66. Olszyk, D.M.; Shiroyama, T.; Novak, J.M.; Johnson, M.G. A rapid-test for screening biochar effects on seed germination. Commun. Soil Sci. Plant Anal. 2018, 49, 2025-2041. [CrossRef]

67. Deenik, J.L.; Cooney, M.J. The potential benefits and limitations of corn cob and sewage sludge biochars in an infertile Oxisol. Sustainability 2016, 8, 131. [CrossRef]

68. Li, Y.; Shen, F.; Guo, H.; Wang, Z.; Yang, G.; Wang, L.; Zhang, Y.; Zeng, Y.; Deng, S. Phytotoxicity assessment on corn stover biochar, derived from fast pyrolysis, based on seed germination, early growth, and potential plant cell damage. Environ. Sci. Pollut. Res. 2015, 22, 9534-9543. [CrossRef]

69. Cheng, C.-H.H.; Lehmann, J.; Thies, J.E.; Burton, S.D.; Engelhard, M.H. Oxidation of black carbon by biotic and abiotic processes. Org. Geochem. 2006, 37, 1477-1488. [CrossRef]

70. Lehmann, J.; Joseph, S.; Thies, J.E.; Rillig, M.C.; Lehmann, J.; Joseph, S. Biochar for Environmental Management; Earthscan: London, UK, 2009; Volume 1, ISBN 9781844076581.

71. Di Lonardo, S.; Vaccari, F.P.; Baronti, S.; Capuana, M.; Bacci, L.; Sabatini, F.; Lambardi, M.; Miglietta, F. Biochar successfully replaces activated charcoal for in vitro culture of two white poplar clones reducing ethylene concentration. Plant Growth Regul. 2013, 69, 43-50. [CrossRef] 